\title{
The Meaningful Mixed Data TOPSIS (TOPSIS-MMD) Method and its Application in Supplier Selection
}

\author{
Sourour AOUADNI ${ }^{1 *}$, Abdelwaheb REBAI ${ }^{2}$, Zenonas TURSKIS ${ }^{3}$ \\ ${ }^{1,2}$ Laboratory of Modeling and Optimization for Decisional, Industrial and Logistic Systems, Faculty of \\ Economics and Management, \\ Route de l'aéroport, Km 4, B.P. 1088, Sfax 3018, Tunisie \\ ${ }^{1 *}$ sourour_aouadni@yahoo.fr (*Corresponding author) \\ ${ }^{3}$ Research Institute of Smart Building Technologies, Faculty of Civil Engineering, Vilnius Gediminas Technical \\ University, \\ Saulètekio al. 11, LT-10223 Vilnius, Lithuania \\ zenonas.turskis@vgtu.lt
}

\begin{abstract}
The TOPSIS method suffers from two major shortcomings (1) the non-meaningfulness of the resulting rankings in mixed data contexts (i.e., the rankings of alternatives may change under admissible transformations of the initial attribute values, in the measurement-theoretic sense of the term), and (2) rank reversals or ranking irregularities(i.e., the rankings of alternatives may change if a new alternative is added to the given offered set of alternatives or an old one is deleted from it or replaced in it). The present research tackles the above shortcomings in order to improve the TOPSIS method by suggesting novel reference points and by extending it to mixed data in a rather defensible manner. Finally, the suggested TOPSIS method (referred to herein as the meaningful mixed data TOPSIS method (TOPSIS-MMD)) is used to solve a mixed data multiattribute supplier selection problem.
\end{abstract}

Keywords: MCDM, TOPSIS-MMD, Normalisation, Admissible transformation, Non-meaningfulness, Mixed data, Rank reversal.

\section{Introduction}

The growth in business is creating a demand for suitable materials, techniques, and research [36]. Selection among multiple discrete alternatives in real business world is a complex multidimensional problem including both qualitative and quantitative factors, such as human resources, operational and financial dimensions, which may be in conflict [35]. The Technique for Order Preference by Similarity to Ideal Solution (TOPSIS) method [12] is one of the well-known classical multiple criteria analysis methods [38]. The main idea of this method is to identify an alternative among a set of alternatives that should have the shortest Euclidean, City block, or Minkowski distance to the positive ideal solution (PIS), and the farthest distance from the negative ideal solution (NIS). The research is based on assumption, that in order to apply standard TOPSIS method, the initial values of attributes must be ratio scaled, monotonic increasing or decreasing, and have commensurable measurement units. This method makes full use of attribute information, provides a complete ranking of alternatives.

The method has a simple process and the number of steps remains the same regardless of the number of attributes. Over the last decades, the number of academic publications dedicated to the study of the TOPSIS method has increased extensively. These studies can be classified into four categories: applications, modifications, extensions and hybridizations. The TOPSIS method is easily applicable to solving many real word problems with a finite number of alternatives in many areas such as [37]:

- Supply chain management and logistics [5], [34];

- Business and marketing management [29], [18];

- Design, engineering and manufacturing systems [31], [32], [27];

- Energy management [7];

- Technology selection [2];

- Health, safety and environment management [30], [1], [9], and so on.

The work of Chen et al. [6], who proposed a new distance approach based on extreme points to improve the standard TOPSIS method, is one of the most important for this research. Jahan et al. [13] used a target-based normalization method in the TOPSIS process to rank and select the optimal material in the engineering design process. Aghajani Mir et al. [16] presented a 
modified normalization method in the standard TOPSIS for solving the Municipal Solid Waste (MSW) problems.

In the literature, the standard TOPSIS method has known various extensions proposed by several researchers. Rebaï [21] proposed a TOPSIS variant called bag based TOPSIS (BB-TOPSIS) method. Further, some works were interested in hybridizing the TOPSIS method with other methods such as the Analytic Hierarchy Process [11], the Analytic Network Process [24], the genetic algorithms [4], the criteria importance through inter criteria correlation, CRITIC, method [15], the step-wise weight assessment ratio analysis, SWARA, method [20], the robust ordinal regression [39], etc. For more details about the standard TOPSIS, Zavadskas et al. [37] have been provided a state-of the-art literature survey on recent development of TOPSIS method. They established a reference repository that includes 105 papers published between 2000 and 2015 .

Despite being extensively applied for solving multiple criteria decision making problems, in the opinion of the authors of this paper, there are two cogent arguments to argue why the standard TOPSIS method should be made "better". First, the standard TOPSIS method is unable to handle properly mixed attribute values (i.e., attribute values having different levels of measurement). This is due to the improper one-size-fits-all normalization strategy [19], [3]. Second, the standard TOPSIS method has been verified to exhibit rank reversals [33], [8]. In this research, our objective is twofold (1) to make the TOPSIS rankings meaningful in mixed data contexts, (2) to enhance its resistance to rank reversals. In order to meet this twofold objective (1) novel reference points must be defined, and (2) as will be referred to as meaningful monotonic normalization methods (MMNMs) must be used. Hereinafter, the research starts by presenting a cardinal (interval or ratio) data TOPSIS method (TOPSIS-CD method, for short). Then, authors' attention is turned to the development of a meaningful mixed data TOPSIS method (TOPSIS-MMD method). Afterward, the TOPSIS-MMD is applied to a multi-attribute supplier selection problem, and close the article with some concluding comments.

\section{From the standard TOPSIS to the TOPSIS-MMD method}

\subsection{Formal description of the problem}

\section{Given:}

- A set A of $m$ predetermined alternatives $a_{i}$ for $i=1$ to $m$,

- $n$ evaluation attributes $C_{j}$ for $j=1$ to $n$,

- A $m \times n$ matrix $\left[a_{i j}\right]$ of attribute values,

$a_{i j}$ the performance value of the alternative $i$ at the criterion $j$.

Goal: Rank the predetermined alternatives.

\subsection{The standard TOPSIS method}

The standard TOPSIS method is a popular MADM ranking method. Its basic principle is that the chosen alternative must have the shortest distance from the positive ideal solution (PIS and the farthest distance from the negative ideal solution (NIS) see Eq. (2) and Eq. (3). Thus, this method uses the previous reference points (PIS and NIS) in order to rank predetermined alternatives. Note that the computation of the proximity of each alternative to PIS and its remoteness from NIS is very often based on the Euclidean distance. Moreover, since the initial attribute values of the different alternatives may be expressed in different units, a pre-processing step is most needed. That is, the various initial attribute values should be normalized. In the literature, there are diverse monotonic normalization methods (MNM), some of them are shown in Table 1 below (see [12], [16], [17]).

The main steps of the standard TOPSIS method are listed below.

Step 1. Structure a performance decision matrix

Let suppose that there are $m$ alternative and $n$ criteria. Each alternative is evaluated with respect 
to the $n$ criteria. Let be the performance value of the alternative $i$ at the criterion $j$.

Step 2. Normalize the performance matrix by using one of the normalization monotonic procedure (see Table 1).

Where:

$-a_{j}^{\max }$ is the maximum performance rating among alternatives for attribute $c_{j}(\mathrm{j}=1,2, . ., \mathrm{n})$

$-a_{j}^{\min }$ is the minimum performance rating among alternatives for attributes $c_{j}(\mathrm{j}=1,2, . ., \mathrm{n})$.

$-a_{j}$ is the performance rating among alternatives for attributes $c_{j}(\mathrm{j}=1,2, . ., \mathrm{n})$.

Step 3. Form the weighted normalized matrix

$v_{i j}=w_{j} r_{i j}$,

$\mathrm{i}=1, \ldots, \mathrm{m} ; \mathrm{j}=1, \ldots, \mathrm{n}$

Table 1. Proposed monotonic normalization methods in TOPSIS

\begin{tabular}{|c|c|c|}
\hline$\sum_{\sum}^{\sum}$ & $\begin{array}{l}\text { Benefit } \\
\text { attribute }\end{array}$ & $\begin{array}{c}\text { Cost } \\
\text { attribute }\end{array}$ \\
\hline 官 & $r_{i j}=\frac{a_{i j}}{\left(\sum_{k=1}^{m} a_{k j}^{2}\right)^{\frac{1}{2}}}$ & $r_{i j}=\frac{\frac{1}{a_{i j}}}{\left(\sum_{k=1}^{m}\left(\frac{1}{a_{k j}}\right)^{2}\right)^{\frac{1}{2}}}$ \\
\hline 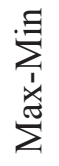 & $r_{i j}=\frac{a_{i j}-a_{j}^{\min }}{a_{j}^{\max }-a_{j}^{\min }}$ & $r_{i j}=\frac{a_{j}^{\max }-a_{i j}}{a_{j}^{\max }-a_{j}^{\min }}$ \\
\hline 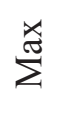 & $r_{i j}=\frac{a_{i j}}{a_{j}^{\max }}$ & $r_{i j}=1-\frac{a_{i j}}{a_{j}^{\max }}$ \\
\hline $\begin{array}{c}\Xi \\
\text { ڤ }\end{array}$ & $r_{i j}=\frac{a_{i j}}{\sum_{k=1}^{m} a_{j}}$ & $r_{i j}=\frac{1 / a_{i j}}{\sum_{k=1}^{m}\left(1 / a_{j}\right)}$ \\
\hline
\end{tabular}

Step 4. Determine PIS, $a^{\max }$, and NIS, $a_{\text {min }}$

For every $j \in j^{\prime}$ define $v_{j}^{\text {max }}=\underset{i}{\max }\left(v_{i j}\right)$,

For every $\mathrm{j} \in \mathrm{j}^{\prime \prime}$ define $v_{j}^{\max }=\underbrace{\min }_{i}\left(v_{i j}\right)$,

For every $\mathrm{j} \in \mathrm{j}^{\prime}$ define

$v_{j}^{\min }=\underbrace{\min }_{i}\left(v_{i j}\right)$, For every $\mathrm{j} \in \mathrm{j}^{\prime \prime}$

define $v_{j}^{\min }=\underbrace{\max }_{i}\left(v_{i j}\right)$,

where $J^{\prime}$ is the set of benefit attributes and $J^{\prime \prime}$ the set of cost attributes.

Step 5. Calculate the separation measures of each alternative $a_{i j}$ from the positive ideal solutionan $d_{i}^{*}$ the negative ideal solution $d_{*_{i}}$ :

$d_{i}^{+}=\left(\sum_{j=1}^{n}\left(v_{i j}-v_{j}^{\max }\right)^{2}\right)^{\frac{1}{2}}$ and

$d_{i}^{-}=\left(\sum_{j=1}^{n}\left(v_{i j}-v_{j}^{\min }\right)^{2}\right)^{\frac{1}{2}}$

Step 6. Compute the relative closeness coefficients $c_{i}$ 's.

$c_{i}=\left(d_{i}^{-}\right) /\left(d_{i}^{+}+d_{i}^{-}\right)$

Step 7. Rank the potential alternatives based on the decreasing values of the $c_{i}$ 's.

\subsection{The TOPSIS-CD method}

The TOPSIS-CD method could be introduced as a modified cardinal TOPSIS method which is meaningful and more resistant to rank reversals than the standard TOPSIS method (see Table 5). To this end, there are used two new and unfamiliar exogenous reference points. The novel reference points will ensure that the rankings of alternatives remain unchanged with the addition of a new alternative or the deletion or replacement of an old one provided that the initial attribute values fall within the limits of the performance classes defined by the new reference points. The interval of the new reference points is longer than it in standard TOPSIS because the $d_{j}$ value is integrated. The idea is to sort the initial 
attribute values in descending order of value for each attribute $C_{j}$, and to compute the maximum difference $d_{j}$ between two consecutive ordered intra-attribute values as in Eq. (7) below:

$d_{j}=\max _{i \leq k \leq(m-1)}\left(a_{(k) j}-a_{(k+1) j}\right)$

Afterward, the new and determined as follows:

$$
\begin{aligned}
& P I S_{j}=a_{j}^{++}=\max _{i \leq k \leq j} a_{i j}+d_{j}, \\
& \left.N I S_{j}=a_{j}^{--}=\max \left(0, \underset{1<k<n}{0 \min } a_{i j}-d_{j}\right)\right)
\end{aligned}
$$

In the TOPSIS-CD, to normalize the ratio and interval attribute values, we will use the Eq. (10) below (see Appendix):

$r_{c}\left(a_{i j}\right)=\frac{a_{i j}-a_{j}^{--}}{a_{j}^{++}-a_{j}^{-}}$

After that, the weighted Euclidean distance is using to compute the separation measures of each alternative $a_{i j}$ from the positive ideal solution $d^{++}$ and the negative ideal solution $d^{--}$:

$d_{i}^{++}=\left(\sum_{j \in C} w_{j}\left(1-r_{i j}^{C}\right)^{2}\right)^{\frac{1}{2}}$

$d_{i}^{--}=\left(\sum_{j \in C} w_{j}\left(r_{i j}^{C}\right)^{2}\right)^{\frac{1}{2}}$

Then, the alternatives ranked, based on the relative closeness coefficients $c_{i}$ 's:

$c_{i}=\frac{d_{i}^{--}}{d_{i}^{++}+d_{i}^{--}}$

Statement 1. The TOPSIS-CD method is meaningful and more resistant to rank reversals than the standard TOPSIS method.

\section{Proof.}

Below, is shown that after admissible transformation, only Max-Min method is meaningful for ratio and interval data (see statement 3 and 4 in the Appendix A).
With the same reasoning, The TOPSIS-CD method is meaningful because the Max-Min method remain meaningful for the new interval of the PIS and NIS.

The admissible transformations of ratio data are of the form: $y_{i j}=k a_{i j}$ with $a>0$.

The Max-Min method gives for benefit performance attribute values:

$$
y_{i j}=\frac{y_{i j}-y_{j}^{--}}{y_{j}^{++}-y_{j}^{--}}=\frac{k a_{i j}-k a_{j}^{--}}{k a_{j}^{++}-k a_{j}^{--}}=\frac{a_{i j}-a_{j}^{--}}{a_{j}^{++}-a_{j}^{--}}=r_{i j}
$$

and for cost attributes:

$y_{i j}=\frac{y_{j}^{++}-y_{i j}}{y_{j}^{++}-y_{j}^{--}}=\frac{k a_{j}^{++}-k a_{i j}}{k a_{j}^{++}-k a_{j}^{--}}=\frac{a_{j}^{++}-a_{i j}}{a_{j}^{++}-a_{j}^{--}}=r_{i j}$

The admissible transformations of interval data are of the form:

$$
y_{i j}=k a_{i j}+b \text { with } a>0 \text { and } b \neq 0 \text {. }
$$

The Max-Min method gives for benefit performance attribute values:

$y_{i j}=\frac{y_{i j}-y_{j}^{--}}{y_{j}^{++}-y_{j}^{--}}=\frac{\left(k a_{i j}+b\right)-\left(k a_{j}^{--}+b\right)}{\left(k a_{j}^{++}+b\right)-\left(k a_{j}^{--}+b\right)}$

$=\frac{a_{i j}-a_{j}^{--}}{a_{j}^{++}-a_{j}^{--}}=r_{i j}$,

and for cost attributes:

$y_{i j}=\frac{\left(y_{j}^{++}+b\right)-\left(y_{i j}+b\right)}{\left(y_{j}^{++}+b\right)-\left(y_{j}^{--}+b\right)}=\frac{\left(k a_{j}^{++}+b\right)-\left(k a_{i j}+b\right)}{\left(k a_{j}^{++}+b\right)-\left(k a_{j}^{--}+b\right)}$

$=\frac{a_{j}^{++}-a_{i j}}{a_{j}^{++}-a_{j}^{--}}=r_{i j}$

2) The TOPSIS-CD method more resistant to rank reversals than the standard TOPSIS method (see Table 5).

The positive ideal solution $a_{j}^{\max }$ in the CDTOPSIS is greater or equal than the PIS in standard TOPSIS method because we add the maximum difference between two consecutive ordered intraattribute values. The same reasoning for PIS in the CD-TOPSIS which is inferior or equal than the PIS in the standard TOPSIS (see formula). The integration of the maximum difference between two consecutive ordered intra-attribute values make the interval of the novel reference points in 
the TOPSIS-CD is $\mathbf{a}_{\mathbf{j}} \in\left[\mathbf{a}_{\mathbf{j}}^{--}, \mathbf{a}_{\mathbf{j}}^{++}\right]$and it is longer than the interval of the reference points in the standard TOPSIS method that is $\mathrm{a}_{\mathrm{j}} \in\left[\mathrm{a}_{\mathrm{j}}^{\min }, \mathrm{a}_{\mathrm{j}}^{\max }\right]$. Then, $\left[\mathrm{a}_{\mathrm{j}}^{\max }, \mathrm{a}_{\mathrm{j}}^{\mathrm{min}}\right] \subset\left[\mathrm{a}_{\mathrm{j}}^{--}, \mathrm{a}_{\mathrm{j}}^{++}\right]_{\text {and if we integer }}^{\mathrm{j}}$ a new alternative (for instance: $a_{j}^{--}$and $a_{j}^{++}$) in the set of alternatives which belongs in this new interval, the chance that the final rank remains the same increase.

For the three phenomenon of rank reversal: If

(1) The addition of a new alternative $a_{j}^{\prime} \in\left[a_{j}^{--}, a_{j}^{++}\right]$,

(2) The replacement of the $a_{j} \in\left[a_{j}^{\min }, a_{j}^{\max }\right]$ by $a_{j}^{\prime} \in\left[a_{j}^{--}, a_{j}^{++}\right]$, and

(3) The removal of an alternative $a_{j} \in\left[a_{j}^{\min }, a_{j}^{\max }\right]$ of the set of alternatives, the TOPSIS-CD method will be more resistant to rank reversals than the standard TOPSIS because $\left[a_{j}^{\max }, a_{j}^{\min }\right] \subset\left[a_{j}^{--}, a_{j}^{++}\right]$.

\subsection{The TOPSIS-MMD method}

The study of the proposed monotonic normalisation methods (presented in Table 1) is meant to ensure the invariance of the rankings of alternatives under admissible transformations of the initial attribute values involved. For ordinal data, Rebaï [21] defined the respective superiority score $(S$-score) and inferiority score ( $I$-score) of an alternative in the set A with respect to attribute $C_{j}$ as

$$
\begin{aligned}
& S_{j}(a)=\operatorname{Card}\left\{b \in A \mid C_{j}(a)>C_{j}(b)\right\} ; \\
& I_{j}(a)=\operatorname{Card}\left\{b \in A \mid C_{j}(a)<C_{j}(b)\right\} ;
\end{aligned}
$$

In the previous formulas, the score $S_{j}(a)$ (resp. $I_{j}(a)$ )is nothing but the number of alternatives $b$ "beaten" by (resp. "beating") alternative $a$. In this work, we propose to transform the ordinal initial attribute values which takes into account the two previous scores. So, for ordinal attribute values, we will use the normalising formula defined by Eq. (16).

$$
r_{O}\left(a_{i j}\right)=\frac{S_{i j}}{S_{i j}+I_{i j}}
$$

Statement 2. The TOPSIS-MMD method is meaningful.

Proof. Let suppose that $m$ alternatives evaluated by ordinal scale (For instance: very Good, good, Moderate) for a criterion $j$. Then, for a criterion $j$ if an alternative $a_{i}$ is superior to $k$ alternatives with $S=k$ and it is inferior to $L$ alternatives with $I=L$. I the $S-I$ scores remain unchangeable when the ordinal scale will be change by another representation (for instance: very high, high, Moderate) and the normalization value and final rank remains the same. For this reason the proposed ordinal normalization is meaningful.

The separation measures of each alternative $a_{i j}$ from the positive ideal solution $d_{i}^{++}$and the negative ideal solution $d_{i}^{--}$are computed by using the weighted Euclidean distance.

$d_{i}^{++}=\left(\begin{array}{l}\sum_{j \in O} w_{j}\left(1-r_{i j}^{O}\right)^{2} \\ +\sum_{j \in C} w_{j}\left(1-r_{i j}^{C}\right)^{2}\end{array}\right)^{\frac{1}{2}}$,

$d_{i}^{--}=\left(\begin{array}{l}\sum_{j \in O} w_{j}\left(r_{i j}^{O}\right)^{2} \\ +\sum_{j \in C} w_{j}\left(r_{i j}^{C}\right)^{2}\end{array}\right)^{\frac{1}{2}}$

Then, alternatives ranked based on the relative closeness coefficients $c_{i}$ 's after to rank the alternatives based on $c_{i}$.

$c_{i}=\frac{d_{i}^{--}}{d_{i}^{++}+d_{i}^{--}}$.

\section{Supplier selection using TOPSIS- MMD in Tunisian medical and surgical centre (PE)}

The supplier selection problem is in essence a mixed data multi-attribute decision making problem and it is one of the most popular applications of the TOPSIS method. Shyur and Shih [25] presented an effective model using both ANP and modified TOPSIS to accommodate the criteria with interdependencies in supplier selection problem. Haldar et al. [10] developed a quantitative approach to select the best supplier considering multi-attribute by integrating Quality Function Deployment (QFD) method with the TOPSIS method. Junior et al. [14] presented a comparative study between the Fuzzy 
AHP and the Fuzzy TOPSIS methods to solve the problem of supplier selection. Rouyendegh and Saputro [23] provided in their study an integrated fuzzy TOPSIS and Multi-Choice Goal Programming (MCGP) method for supplier selection and order allocation under uncertain environments. Wood [34] applied Intuitionistic Fuzzy TOPSIS with Flexible Entropy Weighting to evaluate and select suppliers considering relevant criteria to an oil and gas facilities development project.

In this work, TOPSIS-MMD method is suggested and applied to compute meaningful suitability indexes for suppliers of a Tunisian medical and surgical centre (PE) located in Sfax city. PE centre has more than 40 specialists in their fields, in surgery, anaesthesia and medicine. It incorporate an emergency centre, a medical imaging centre, laboratory, day hospital and pharmaceutical shops for the supply of medicine to patient. For this pharmaceutical, there are two types of products: Drug and medical accessories. Pharmaceutical shops demand the medical accessories of ten main suppliers formally symbolized $\left(a_{1}-a_{10}\right)$ located in Sfax, Sousse and Tunis. They suppliers should be ranked by using five evaluation attributes (two ratio attributes and three ordinal ones). The ordinal attributes are quality, service, and performance history whereas the ratio attributes are the geographical location and the delivery time. For the ordinal attributes, the suppliers are rated on an ordinal scale made up of the following three discrete gradations: Very Good (VG), Good (G), and Intermediate (I). The respective weights of the attributes are: $0.3,0.2,0.15,0.1$ and 0.25 .

Table 2. Decision matrix

\begin{tabular}{|c|c|c|c|c|c|}
\hline & \multicolumn{3}{|c|}{ Ordinal attributes } & \multicolumn{2}{|c|}{ Ratio attributes } \\
\hline & 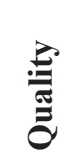 & : & 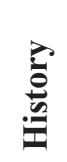 & 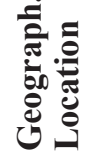 & 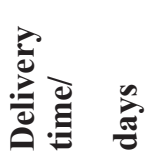 \\
\hline & $\mathrm{C}_{1}$ & $\mathrm{C}_{2}$ & $\mathrm{C}_{3}$ & $\mathrm{C}_{4}$ & $\mathrm{C}_{5}$ \\
\hline$a_{1}$ & $\mathrm{VG}$ & $\mathrm{VG}$ & $\mathrm{G}$ & 10 & 10 \\
\hline$a_{2}$ & $\mathrm{VG}$ & $\mathrm{G}$ & $\mathrm{VG}$ & 7 & 13 \\
\hline$a_{3}$ & $\mathrm{VG}$ & $\mathrm{I}$ & $\mathrm{I}$ & 15 & 15 \\
\hline$a_{4}$ & $\mathrm{G}$ & $\mathrm{G}$ & $\mathrm{I}$ & 9 & 10 \\
\hline$a_{5}$ & $\mathrm{G}$ & $\mathrm{I}$ & $\mathrm{I}$ & 140 & 20 \\
\hline$a_{6}$ & $\mathrm{G}$ & $\mathrm{VG}$ & $\mathrm{VG}$ & 13 & 8 \\
\hline$a_{7}$ & $\mathrm{G}$ & $\mathrm{G}$ & $\mathrm{G}$ & 280 & 11 \\
\hline$a_{8}$ & $\mathrm{G}$ & $\mathrm{I}$ & $\mathrm{G}$ & 140 & 15 \\
\hline$a_{9}$ & $\mathrm{VG}$ & $\mathrm{VG}$ & $\mathrm{VG}$ & 11 & 10 \\
\hline$a_{10}$ & $\mathrm{VG}$ & I & $\mathrm{G}$ & 280 & 17 \\
\hline
\end{tabular}

Step 2. Performing meaningful monotonic normalisations

The TOPSIS-MMD method is applied to rank these alternatives. At the start, the $d_{j}$ 's calculated using Eq. (7):

The descending order of values for the attribute geographical location is: $280,280,140,140,15$, $13,11,10,9,7$. Thus

$d_{4}=\max _{1 \leq i \leq 10}(0,140,0,125,2,2,1,1,2)=140$

The descending order of values for the attribute delivery time is: $20,17,15,15,13,11,10,10,10$, 8. Thus,

$d_{5}=\max _{1 \leq i \leq 10}(3,2,0,2,2,1,0,0,2)=3$

Positive and negative ideals are computed using Eq. (8) and Eq. (9):

$a_{4}^{++}=420 ;-{ }^{--} 0$;

$a_{5}^{++}=23 ; a_{5}^{--}=5 ;$

The normalized performance attribute values for the geographical location which is a cost ratio attribute, are given by: $r_{i 4}=\frac{420-a_{i 4}}{420}$.

The normalized attribute values for the delivery time which is a cost ratio attribute, are given by: $r_{i 5}=\frac{23-a_{\mathrm{i} 5}}{18}$.

Further, the $S$-scores and $I$-scores for the six suppliers and the normalized values are determined. Results of Table 3 are obtained when the formulas (14)-(15) are applied.

Table 3. Superiority, inferiority scores and normalised values

\begin{tabular}{|l|c|c|c|c|c|c|}
\hline \multirow{2}{*}{ Suplier } & \multicolumn{3}{|c|}{ S-score } & \multicolumn{3}{c|}{ I-score } \\
\cline { 2 - 7 } & $\mathbf{C}_{\mathbf{1}}$ & $\mathbf{C}_{\mathbf{2}}$ & $\mathbf{C}_{\mathbf{3}}$ & $\mathbf{C}_{\mathbf{1}}$ & $\mathbf{C}_{\mathbf{2}}$ & $\mathbf{C}_{\mathbf{3}}$ \\
\hline$a_{1}$ & 5 & 7 & 5 & 0 & 0 & 3 \\
\hline$a_{2}$ & 5 & 4 & 7 & 0 & 3 & 0 \\
\hline$a_{3}$ & 5 & 0 & 0 & 0 & 6 & 5 \\
\hline$a_{4}$ & 0 & 4 & 0 & 5 & 3 & 5 \\
\hline$a_{5}$ & 0 & 0 & 0 & 5 & 6 & 5 \\
\hline$a_{6}$ & 0 & 7 & 7 & 5 & 0 & 0 \\
\hline$a_{7}$ & 0 & 4 & 0 & 5 & 3 & 5 \\
\hline$a_{8}$ & 0 & 0 & 0 & 5 & 6 & 5 \\
\hline$a_{9}$ & 5 & 7 & 7 & 0 & 0 & 0 \\
\hline$a_{10}$ & 5 & 0 & 5 & 0 & 6 & 3 \\
\hline
\end{tabular}


After the application of the different steps of the TOPSIS-MMD method, the final ranks of the suppliers are determined showing IGE as the best with a meaningful suitability index of 0.86 . The second supplier is $a_{1}$ followed by $a_{2}$. The ranks of the suppliers based on decreasing values of their meaningful suitability indexes are shown in Table 4.

Table 4. The weighted normalised matrix

\begin{tabular}{|c|c|c|c|c|c|c|c|c|c|}
\hline \multirow{2}{*}{ 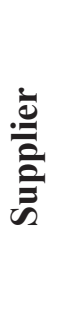 } & \multicolumn{5}{|c|}{ Normalised matrix } & \multicolumn{2}{|c|}{ 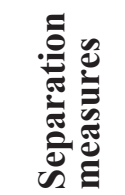 } & \multicolumn{2}{|c|}{ 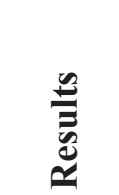 } \\
\hline & $\circlearrowright$ & $v^{2}$ & $U^{r}$ & U & $U^{n}$ & $\frac{\ddagger}{0}$ & 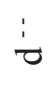 & $\bar{n}$ & $\begin{array}{l}\text { चै } \\
\text { 气 }\end{array}$ \\
\hline 8 & - & - & $\begin{array}{l}\text { S. } \\
0\end{array}$ & $\hat{o}$ & $\stackrel{\mathbb{2}}{0}$ & तิ & $\begin{array}{l}\infty \\
\infty \\
0\end{array}$ & $\begin{array}{l}\bar{\infty} \\
0 \\
0\end{array}$ & $\sim$ \\
\hline o & - & $\tilde{n}$ & - & $\stackrel{\infty}{0}$ & $\begin{array}{l}n \\
n \\
0\end{array}$ & సે & $\stackrel{\infty}{\infty}$ & 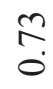 & $m$ \\
\hline o & - & 0 & 0 & $\stackrel{\circ}{\circ}$ & $\stackrel{+}{\stackrel{0}{0}}$ & $\begin{array}{l}n \\
0 \\
0\end{array}$ & $\begin{array}{l}0 \\
\stackrel{0}{0} \\
0\end{array}$ & $\ddot{0}$ & $v$ \\
\hline o & 0 & $\tilde{n}$ & 0 & $\hat{o}$ & $\stackrel{\mathbb{2}}{0}$ & $\stackrel{\vec{F}}{0}$ & ñ? & 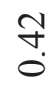 & r \\
\hline$\sigma^{\prime \prime}$ & 0 & 0 & 0 & i. & $\frac{0}{\stackrel{0}{0}}$ & $\bar{\sigma}$ & 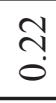 & $\stackrel{a}{\circ}$ & 은 \\
\hline$\sigma^{\circ}$ & 0 & - & - & $\stackrel{\circ}{\circ}$ & $\begin{array}{l}\infty \\
\dot{0}\end{array}$ & $\stackrel{n}{n}$ & $\underset{0}{\stackrel{\infty}{0}}$ & $\begin{array}{l}\infty \\
n \\
0\end{array}$ & $\nabla$ \\
\hline or & 0 & $\tilde{n}$ & 0 & $\stackrel{m}{?}$ & $\underset{0}{0}$ & $\stackrel{+}{\stackrel{+}{0}}$ & $\stackrel{?}{\stackrel{0}{\circ}}$ & $\begin{array}{l}0 \\
\text { ?ִ } \\
0\end{array}$ & $\infty$ \\
\hline $0^{\infty}$ & 0 & 0 & 0 & 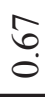 & $\stackrel{+}{+}$ & $\begin{array}{l}n \\
\infty \\
0\end{array}$ & $\hat{n}$ & $\stackrel{?}{0}$ & o \\
\hline $0^{\circ}$ & - & - & 一 & $\hat{o}$ & $\stackrel{N}{\stackrel{0}{0}}$ & $\stackrel{ \pm}{ \pm}$ & $\hat{o}$ & $\begin{array}{l}\stackrel{0}{\infty} \\
\stackrel{0}{0}\end{array}$ & - \\
\hline $0^{5}$ & - & 0 & $\stackrel{\widetilde{\sigma}}{0}$ & $\stackrel{m}{?}$ & $\stackrel{m}{\dddot{m}}$ & $\stackrel{\sigma}{0}$ & 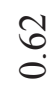 & ڤn & $n$ \\
\hline
\end{tabular}

Unlike the standard TOPSIS method, the final rank remains the same on the CD-TOPSIS method after the integration of a new alternative $\left(A_{11}\right)$ to the set of alternatives. Table 5 presents the final rank in these two methods and show that the final rank remains the same on the CDTOPSIS after add a new alternative. We note that the supplier $\mathrm{A}_{6}$ is always the best.
Table 5. Comparison between CD-TOPSIS and Standard TOPSIS

\begin{tabular}{|c|c|c|c|c|c|c|c|c|}
\hline & \multicolumn{2}{|c|}{$\begin{array}{l}\text { Standard } \\
\text { TOPSIS }\end{array}$} & \multicolumn{2}{|c|}{$\begin{array}{l}\text { Standard } \\
\text { TOPSIS } \\
\text { with new } \\
\text { alternative }\end{array}$} & \multicolumn{2}{|c|}{$\begin{array}{l}\text { CD- } \\
\text { TOPSIS }\end{array}$} & \multicolumn{2}{|c|}{$\begin{array}{l}\text { CD- } \\
\text { TOPSIS } \\
\text { with new } \\
\text { alternative }\end{array}$} \\
\hline A & 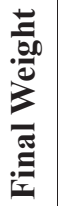 & 氠 & 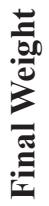 & 氠 & 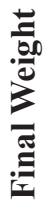 & 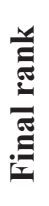 & 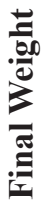 & 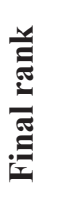 \\
\hline 1 & $\stackrel{\infty}{0}$ & $N$ & $\ddot{0}$ & 一 & $\stackrel{\infty}{0}$ & $N$ & $\stackrel{\infty}{0}$ & $N$ \\
\hline 2 & $\ddot{0}$ & $m$ & $\hat{0}$ & $m$ & $\hat{\sigma}$ & $m$ & $\dot{0}$ & $m$ \\
\hline 3 & ? & $\forall$ & $\stackrel{0}{0}$ & $\nabla$ & $\stackrel{0}{0}$ & ナ & $\stackrel{0}{0}$ & $\checkmark$ \\
\hline 4 & $\stackrel{\infty}{0}$ & $N$ & $\stackrel{0}{0}$ & $\nabla$ & $\stackrel{\infty}{0}$ & $N$ & $\stackrel{\infty}{\infty}$ & $N$ \\
\hline 5 & ? & 6 & $\stackrel{\infty}{0}$ & $N$ & $\tilde{0}$ & 6 & $\stackrel{+}{\circ}$ & 6 \\
\hline 6 & 一 & 一 & $\stackrel{+}{\circ}$ & 6 & $\stackrel{0}{0}$ & 一 & व̊ & $\longrightarrow$ \\
\hline 7 & $\stackrel{\nabla}{\circ}$ & $n$ & $\stackrel{+}{\circ}$ & $m$ & $\stackrel{0}{0}$ & $\nabla$ & $\begin{array}{l}0 \\
0\end{array}$ & $\forall$ \\
\hline 8 & $\ddot{0}$ & 6 & $\ddot{n}$ & $n$ & $\ddot{n}$ & $n$ & ? & $n$ \\
\hline 9 & $\stackrel{\infty}{0}$ & $N$ & $\ddot{0}$ & $\neg$ & $\stackrel{\infty}{0}$ & $N$ & $\stackrel{\infty}{0}$ & $N$ \\
\hline 10 & 0 & $\lambda$ & $\ddot{0}$ & 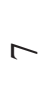 & ?’ & 6 & $\stackrel{+}{\dot{0}}$ & 6 \\
\hline 11 & & & ํ. & $\infty$ & & & ㅁ & $N$ \\
\hline
\end{tabular}

\section{Concluding comments}

The standard TOPSIS method is one of the most popular MCDM methods which is applied to solve numerous real-world problems. This method has known several applications, modifications, extensions, and hybridizations. This method suffers from two prominent defects, namely, the non-meaningfulness of the resulting rankings in mixed data contexts and rank reversals with the addition of a new alternative or the deletion or replacement of an old one. For these two reasons, 
efforts are focused on making the TOPSIS method better. For this reason, study of the meaningfulness of diverse monotonic normalization methods applied in the standard TOPSIS method is presented. Then, based on study results, a cardinal data TOPSIS developed by defining new and unfamiliar reference points to enhance its resistance to rank reversals. In addition, the TOPSIS-MMD method, which is founded on the above novel reference points and specialized normalization methods, is proposed. In particular, a meaningful normalization method is used for ordinal data. The TOPSIS-MMD method is understandable, easily applicable and trustworthy. And, the proposed method was applied for solving the supplier selection problem in Tunisian medical and surgical centre (PE) located in Sfax city. In future, the proposed method will be applied to solve other real-world problems such as green supplier, facility location, and project portfolio selection problems, etc.

\section{Appendix A.}

\section{A.1 The concept of meaningfulness}

The concept of meaningfulness is a cornerstone concept in this work. Roberts [22] wrote "A statement involving numerical scales is meaningful if and only if its truth (or falsity) remains unchanged under all the admissible transformations of all the scales involved." Suppes and Zinnes [28] defined the meaningfulness concept as follows: "A numerical statement is meaningful if and only if its truth (or falsity) is constant under admissible scale transformations of any of its numerical assignments, that is, any of its numerical functions expressing the results of measurement".

\section{A.2 Types of data and admissible transformations}

Scales were introduced to model the link between the empirical relational system and the numerical relational system created by the measurement process. Five types of scales [39], [37] could be distinguished. Stevens in 1946 proposed the representational theory of measurement as a classification of scale types based on the properties of scale that are captured by studying admissible transformations of scale.

Table 6. Scale types and their admissible transformations.

\begin{tabular}{|c|c|c|}
\hline $\begin{array}{l}\text { Scale } \\
\text { type }\end{array}$ & $\begin{array}{l}\text { Admissible } \\
\text { transformation }\end{array}$ & Example \\
\hline Absolute & $\Phi o f(x)=f(x)$ (identity) & Counting \\
\hline Ratio & $\begin{array}{l}\Phi \circ f(x)=\alpha f(x), \\
\alpha>0(\text { similarity })\end{array}$ & Mass \\
\hline Interval & $\begin{array}{l}\Phi \circ f(x)=\alpha f(x)+\beta \\
\alpha>0(\text { positive linear })\end{array}$ & Temperature \\
\hline Ordinal & $\begin{array}{l}\Phi \circ f(x)=\alpha f(x)+\beta, \alpha>0 \\
\text { (monotone increasing) }\end{array}$ & Preference \\
\hline Nominal & $\Phi($ any one to one $)$ & $\begin{array}{l}\text { Curricular } \\
\text { codes }\end{array}$ \\
\hline
\end{tabular}

Hereafter, we are interested in studying the meaningfulness of the monotonic normalisation methods shown in Table 6 .

Statement 3. All the proposed normalisation methods are meaningful for ratio data.

Proof. We will analyse in turn the case of ratio data and the case of interval data. The proofs are presented in Table 7.

Statement 4. Among the proposed normalisation methods, the Max-Min method is the only one which is meaningful for interval attribute values.

Statement 5. None of the proposed normalisation methods is meaningful for ordinal data.

Proof. Trivial 
Table 7. A Scale types and their admissible transformations

\begin{tabular}{|c|c|}
\hline NM & (b)-benefit attributes; $(c)$-cost attributes \\
\hline \multicolumn{2}{|c|}{ 1) The case of ratio data $y=a x$} \\
\hline $\begin{array}{c}\text { Vector } \\
(b)\end{array}$ & $r(y)=\frac{y}{\left(\sum_{i}^{m} y^{2}\right)^{0.5}}=\frac{a x}{\left(\sum_{i}^{m}(a x)^{2}\right)^{0.5}}=\frac{x}{\left(\sum_{i}^{m} x^{2}\right)^{0.5}}=r(x)$ \\
\hline (c) & $r(y)=\frac{\frac{1}{y}}{\left(\sum_{i}^{m}\left(\frac{1}{y}\right)^{2}\right)^{0.5}}=\frac{\frac{a}{x}}{\left(\sum_{i}^{m}\left(\frac{a}{x}\right)^{2}\right)^{0.5}}=\frac{\frac{1}{x}}{\left(\sum_{i}^{m}\left(\frac{1}{x}\right)^{2}\right)^{0.5}}=r(x)$ \\
\hline $\begin{array}{l}\text { Max-min } \\
\text { (b) }\end{array}$ & $r(y)=\frac{y-y^{\min }}{y^{\max }-y^{\min }}=\frac{a x-a x^{\min }}{a x^{\max }-a x^{\min }}=\frac{x-x^{\min }}{x^{\max }-x^{\min }}=r(x)$ \\
\hline (c) & $r(y)=\frac{y^{\max }-y}{y^{\max }-y^{\min }}=\frac{a x^{\max }-a x}{a x^{\max }-a x^{\min }}=\frac{x^{\max }-x}{x^{\max }-x^{\min }}=r(x)$ \\
\hline $\begin{array}{l}\operatorname{Max} \\
(b)\end{array}$ & $r(y)=\frac{y}{y^{\max }}=\frac{a x}{a x^{\max }}=\frac{x}{x^{\max }}=r(x)$ \\
\hline$(c)$ & $r(y)=1-\frac{y}{y^{\max }}=1-\frac{a x}{a x^{\max }}=\frac{x}{x^{\max }}=r(x)$ \\
\hline $\begin{array}{l}\text { Sum } \\
(b)\end{array}$ & $r(y)=\frac{y}{\sum_{i}^{m} y}=\frac{a x}{\sum_{i}^{m}(a x)}=\frac{x}{\sum_{i}^{m} x}=r(x)$ \\
\hline (c) & $r(y)=\frac{\frac{1}{y}}{\sum_{i}^{m} \frac{1}{y}}=\frac{\frac{a}{y}}{\sum_{i}^{m}\left(\frac{a}{y}\right)}=\frac{\frac{1}{x}}{\sum_{i}^{m} \frac{1}{x}}=r(x)$ \\
\hline \multicolumn{2}{|c|}{ 2) The case of interval data the admissible transformations $f(x)=a x+b$ with $a>0$ and $b \neq$} \\
\hline $\begin{array}{l}\text { Vector } \\
\text { (b) }\end{array}$ & $r(y)=\frac{y}{\left(\sum_{i}^{m} y^{2}\right)^{0.5}}=\frac{a x+b}{\left(\sum_{i}^{m}(a x+b)^{2}\right)^{0.5}} \neq \frac{x}{\left(\sum_{i}^{m} x^{2}\right)^{0.5}}=r(x)$ \\
\hline (c) & $r(y)=\frac{\frac{1}{y}}{\left(\sum_{i}^{m}\left(\frac{1}{y}\right)^{2}\right)^{0.5}}=\frac{\frac{a}{x}+b}{\left(\sum_{i}^{m}\left(\frac{a}{x}+b\right)^{2}\right)^{0.5}} \neq \frac{\frac{1}{x}}{\left(\sum_{i}^{m}\left(\frac{1}{x}\right)^{2}\right)^{0.5}}=r(x)$ \\
\hline $\begin{array}{l}\operatorname{Max}- \\
\min (b)\end{array}$ & $r(y)=\frac{y-y^{\min }}{y^{\max }-y^{\min }}=\frac{(a x+b)-\left(a x^{\min }+b\right)}{\left(a x^{\max }+b\right)-\left(a x^{\min }+b\right)}=\frac{x-x^{\min }}{x^{\max }-x^{\min }}=r(x)$ \\
\hline (c) & $r(y)=\frac{y^{\max }-y}{y^{\max }-y^{\min }}=\frac{\left(a x^{\max }+b\right)-(a x+b)}{\left(a x^{\max }+b\right)-\left(a x^{\min }+b\right)}=\frac{x^{\max }-x}{x^{\max }-x^{\min }}=r(x)$ \\
\hline $\operatorname{Max}(b)$ & $r(y)=\frac{y}{y^{\max }}=\frac{a x+b}{a x^{\max }+b} \neq \frac{x}{x^{\max }}=r(x)$ \\
\hline$(c)$ & $r(y)=1-\frac{y}{y^{\max }}=1-\frac{a x+b}{a x^{\max }+b} \neq \frac{x}{x^{\max }}=r(x)$ \\
\hline $\operatorname{Sum}(b)$ & $r(y)=\frac{y}{\sum_{i}^{m} y}=\frac{a x+b}{\sum_{i}^{m}(a x+b)} \neq \frac{x}{\sum_{i}^{m} x}=r(x)$ \\
\hline (c) & $r(y)=\frac{\frac{1}{y}}{\sum_{i}^{m} \frac{1}{y}}=\frac{\frac{a}{y}+b}{\sum_{i}^{m}\left(\frac{a}{y}+b\right)} \neq \frac{\frac{1}{x}}{\sum_{i}^{m} \frac{1}{x}}=r(x)$ \\
\hline
\end{tabular}




\section{REFERENCES}

1. AGHAJANI MIR, M., TAHEREI GHAZVINEI, P., SULAIMAN, N. M. N., BASRI, N. E. A., SAHERI, S., MAHMOOD, N. Z., JAHAN. A., BEGUM, R. A. \& AGHAMOHAMMADI, N. (2016). Application of TOPSIS and VIKOR improved versions in a multi criteria decision analysis to develop an optimized municipal solid waste management model, Journal of Environmental Management, $166,109-115$.

2. ALIAKBARI NOURI, F., KHALILI ESBOUEI, S. \& ANTUCHEVICIENE, J. (2015). A hybrid MCDM approach based on fuzzy ANP and fuzzy TOPSIS for technology selection, Informatica, 26(3), 369-388.

3. AOUADNI, S. \& REBAÏ, A. (2015). Meaningful mixed data TOPSIS analysis with application to supplier selection. In 23rd International Conference on Multiple Criteria Decision Making (MCDM 2015) - Bridging Disciplines. August 2nd-7th, Hamburg, Germany.

4. BANWET, D. K. \& MAJUMDAR, A. (2014). Comparative analysis of AHPTOPSIS and GA-TOPSIS methods for selection of raw materials in textile industries. In Proceedings of the 2014 International Conference on Industrial Engineering and Operations Management Bali, Indonesia, January (pp. 7-9).

5. CHANG, K.-L., LIAO, S.-K., TSENG, T.W. \& LIAO, C.-Y. (2015). An ANP based TOPSIS approach for Taiwanese service apartment location selection, Asia Pacific Management Review, 20, 49-55.

6. CHEN, Y., LI, W. K. \& LIU, S.-F. (2011). An OWA-TOPSIS method for multiple criteria decision analysis, Expert Systems with Applications, 38(5), 5205-5211.

7. ERDOGAN, M. \& KAYA, I. (2016). A combined fuzzy approach to determine the best region for a nuclear power plant in Turkey, Applied Soft Computing, 39, 84-93.

8. GARCÍA-CASCALES, M. S. \& LAMATA, M. T. (2012). On rank reversal and TOPSIS method, Mathematical and Computer Modelling, 56(5), 123-132.

9. GUL, M. \& FUAT GUNERI, A. (2016). A fuzzy multi criteria risk assessment based on decision matrix technique: A case study for aluminium industry, Journal of Loss Prevention in the Process Industries, 40, 89-100.
10. HALDAR, A., BANERJEE, D., RAY, A. \& GHOSH, S. (2012). An integrated approach for supplier selection. International conference on modelling optimization and computing, Procedia Engineering, 38, 2087-2102.

11. HANINE, M., BOUTKHOUM, O., TIKNIOUINE, A. \& AGOUTI, T. (2016). Application of an integrated multi criteria decision making AHP TOPSIS methodology for ETL software selection, SpringerPlus, $5(1), 263$

12. HWANG, C.L. \& YOON, K. (1981). Multiple Attribute Decision Methods and Applications. Berlin, Heidelberg: Springer.

13. JAHAN, A., BAHRAMINASAB, M. \& EDWARDS, K. L. (2012). A target-based normalization technique for materials selection, Materials and Design, 35, 647-654.

14. JUNIOR, F. R. L., OSIRO, L. \& CARPINETTI, L. C. R. (2014). A comparison between fuzzy AHP and fuzzy TOPSIS methods to supplier selection, Applied Soft Computing, 21, 194-209.

15. KAZAN, H. \& OZDEMIR, O. (2014). Financial performance assessment of large scale conglomerates via TOPSIS and CRITIC methods, International Journal of Management and Sustainability, 3(4), 203-224.

16. LAI, Y. J., LIU, T. Y. \& HWANG, C. L. (1994). TOPSIS for MODM, European Journal of Operational Research, 76(3), 486-500.

17. LAKSHMI, T. M. \& VENKATESAN, V. P. (2014). A Comparison of various normalization in Techniques for Order Performance by Similarity to Ideal Solution (TOPSIS), International Journal of Computing Algorithm, 3, 882-888.

18. LOURENZUTTI, R. \& KROHLING, R. A. (2016). A generalized TOPSIS method for group decision making with heterogeneous information in a dynamic environment, Information Sciences, 330, 1-18.

19. MARTEL, J. M. \& ROY, B. (2002). Analyse De La Signifiance De Diverses Procedures D'agrégation Multicritère, Annales $d u$ LAMSADE 1, Université Paris-Dauphine

20. NGUYEN, H.-T., DAWAL, S. Z. M., NUKMAN, Y., AOYAMA, H. \& CASE, K. (2015). An integrated approach of fuzzy linguistic preference based AHP and fuzzy 
COPRAS for machine tool evaluation, $P L O S$ One, 10(9): e0133599.

21. REBAI, A. (1993). BBTOPSIS: a bag based technique for order preference by similarity to ideal solution, Fuzzy Sets and Systems, 60(2), 143-162.

22. ROBERTS, F. S. (1979). Encyclopedia of Mathematics and its Applications, vol. 7, Measurement Theory, Addison-Wesley, Reading, Mass.

23. ROUYENDEGH, B. D. \& SAPUTRO, T. E (2014). Supplier selection using integrated fuzzy TOPSIS and MCGP: a case study, Procedia-Social and Behavioral Sciences, Volume 116, 3957-3970.

24. SHAHROUDI, K. \& ROUYDEL, H. (2012). Using a multi-criteria decision making approach (ANP-TOPSIS) to evaluate suppliers in Iran's auto industry, International Journal of Applied Operational Research 2(2), 37-48.

25. SHYUR, H. J. \& SHIH, H. S. (2006) (TOPSIS). International Journal of Computing Algorithm, (03), 882-888. A hybrid MCDM model for strategic vendor selection, Mathematical and Computer Modeling, 44(7), 749-761.

26. STEVENS, S. S. (1946). On the theory of scales of measurement, Science, 103, 677-680.

27. SUN, L., MA, J., ZHANG, Y., DONG, H. \& HUSSAIN, F. K. (2016). CloudFuSeR: Fuzzy ontology and MCDM based cloud service selection, Future Generation Computer Systems, 57, 42-55.

28. SUPPES, P. \& ZINNES, J. (1963). Basic measurement theory. In: R. D. Luce, R. R. Bush, \& E. Galanter (Eds.), Handbook of Mathematical Psychology, vol. I. 1-76, New York, Wiley.

29. TAVANA, M., ZAROOK, Y. \& J. SANTOSARTEAGA F. (2015). An integrated threestage maintenance scheduling model for unrelated parallel machines with aging effect and multi-maintenance activities, Computers \& Industrial Engineering, 83, 226-236.

30. TURSKIS, Z. \& JUODAGALVIENĖ, B. (2016). A novel hybrid multi-criteria decisionmaking model to assess a stairs shape for dwelling houses, Journal of Civil Engineering and Management, 22(8), 1078-1087.
31. TURSKIS, Z., DANIŪNAS, A., ZAVADSKAS, E. K. \& MEDZVIECKAS, J. (2016). Multicriteria evaluation of building foundation alternatives, Computer-Aided Civil and Infrastructure Engineering, 31(9), 717-729.

32. WANG, X., CHAN, H. K, \& LI, D. (2015a). A case study of an integrated fuzzy methodology for green product development, European Journal of Operational Research, 241, 212-223.

33. WANG, Y.-M. \& LUO, Y. (2009). On rank reversal in decision analysis, Mathematical and Computer Modelling, 49, (5-6), 1221-1229.

34. WOOD, D. A. (2016). Supplier selection for development of petroleum industry facilities, applying multi-criteria decision making techniques including fuzzy and intuitionistic fuzzy TOPSIS with flexible entropy weighting, Journal of Natural Gas Science and Engineering, 28, 594-612.

35. WU, J. (2015). A SD-IITFOWA operator and TOPSIS based approach for MAGDM problems with intuitionistic trapezoidal fuzzy numbers, Technological and Economic Development of Economy, 21(1), 28-47.

36. ZAGORSKAS, J., ZAVADSKAS, E. K., TURSKIS, Z., BURINSKIENE, M., BLUMBERGA, A. \& BLUMBERGA, D. (2014). Thermal insulation alternatives of historic brick buildings in Baltic Sea Region, Energy and Buildings, 78, 35-42.

37. ZAVADSKAS, E. K., MARDANI, A., TURSKIS, Z., JUSOH, A. \& NOR, K. M. (2016). Development of TOPSIS method to solve complicated decision-making problems-An overview on developments from 2000 to 2015, International Journal of Information Technology \& Decision Making, 15(03), 645-682.

38. ZAVADSKAS, E. K., TURSKIS, Z. \& KILDIENE, S. (2014). State of art surveys of overviews on MCDM/MADM methods, Technological and Economic Development of Economy, 20(1), 165-179.

39. ZIELNIEWICZ, P. (2013). Robust ordinal regression applied to TOPSIS, Multiple Criteria Decision Making, 8, 179-197. 
